\title{
A MÚSICA NO PROCESSO DE CUIDAR DE CLIENTES COM SÍNDROME NEUROLÓGICA DECORRENTE DA AIDS.
}

\author{
Alcione Leite da Silva*
}

RESUMO: Neste artigo abordo a música no processo de cuidar de clientes com síndrome neurológica decorrentes da AIDS, subsidiada pelo sistema conceitual de Rogers. Relato os benefícios da utilização da música como meio para facilitar a interação com o cliente incapacitado de se expressar verbalmente, bem como, para harmonizar seu campo energético.

ABSTRACT: This paper discusses the use of music, along with Rogers' conceptual systems, in the process of caring for clients with neurological syndrome related to AIDS. I report the benefits of utilizing music as a means of facilitating interaction with a client who was unable to communicate verbally, as well as in order to harmonize his energy field.

\section{INTRODUÇÃO}

A síndrome neurológica ( $\mathrm{SN}$ ) vem sendo abordada como decorrente da ação direta do vírus da imunodeficiência humana (HIV) no cérebro ${ }^{(5)}$, bem como das infecções oportunistas do SNC (8). Algumas das infecções que afetam o SNC e são prevalentes em clientes com AIDS incluem: meningite, encefalite e leucoencefalopatia multifocal progressiva ${ }^{(8)}$. Os clientes com SN podem apresentar um ou mais dos seguintes comportamentos ou características: deficits de memória recente e/ou remota, incapacidade de desempenhar ou manter as atividades da vida cotidiana, comportamentos socialmente inaceitáveis, raiva, hostilidade, letargia ${ }^{(8)}$. Nos estágios mais avançados de comprometimento cerebral, estes clientes podem ser vistos como seres incapazes de interagir com o meio ambiente, em virtude das dificuldades de exteriorizarem suas consciências. Conseqüentemente, eles podem estar sujeitos a estímulos inadequados por parte do ambiente. A enfermeira, considerada como parte do ambiente do cliente e de sua família, tem papel primordial na defesa dos interesses do cliente, e na busca de formas de cuidar que facilitem o processo do viver e experienciar a doença.
SER HUMANO E MEIO AMBIENTE SÃO CAMPOS DE ENERGIA EM INTERAÇÃO CONTÍNUA, MÚTUA E SIMULTÂNEA.

O sistema conceitual (6) concebe o cliente como um ser unitário, possuindo campo de energia que coexiste com o campo de energia ambiental. Estes campos são sistemas abertos e estão continuamente trocando matéria e energia entre si.

Os princípios da homodinâmica (integralidade, ressonância e helicidade), propostos por ROGERS (6) , postulam a natureza e direção da mudança, ou seja, do processo evolucionário dos campos humano e ambiental (CHA). O princípio da integralidade estabelece que o processo de interação entre os CHA é contínuo, mútuo e simultâneo. O princípio da ressonância postula que mudanças nos $\mathrm{CHA}$ se propagam em ondas. Essas mudanças são contínuas de baixa para alta frequência dos padrões de onda. A vida é uma manifestação de vibrações rítmicas de ondas que emergem da repadronização contínua dos CHA. Variam as velocidades, as amplitudes e o comprimento das ondas, mas elas estão sempre presentes. O princípio da helicidade estabelece que a natureza e direção da mudança dos padrões das CHA é contínua, inovadora, probabilística e caracterizada por níveis crescentes de complexidade e heterogeneidade. Os prin-

\footnotetext{
* Enfermeira, Mestre em Enfermagem, professora assistente do Departamento de Enfermagem da Universidade Federal de Santa Catarina.
} 
cípios da homodinâmica possibilitam ao enfermeiro reconhecer a dinâmica das relações entre $\mathrm{CHA}$, detectar as disritmias destas relações e prever o curso probabilístico da evoluç̃óes destes campos. Deste modo, o enfermeiro poderá propor ações com fins a redirecionar o curso rítmico das relações entre $\mathrm{CHA}$.

A partir da perspectiva rogeriana, a interação é uma condição sempre presente na vida do ser humano, mesmo quando ele, sob o ponto de vista físico, tem dificuldade ou incapacidade para exteriorizar sua consciência (incluindo os vários estágios do coma). A interação com clientes que apresentam estes padrões de campo energético pode se dar através do estímulo verbal, da música, do toque físico, do toque terapêutico (imposição de mãos), da cor (cromoterapia) e até mesmo de pensamentos, sentimentos e emoções de quem proporciona o cuidado.

\section{A MÚSICA AUXILIA NA CANALIZAÇ̃̃O INTERNA} DAS ENERGIAS, EXPLICITANDO O IMPLICITO, DESPERTANDO A CONSCIÊNCIA DO SER PARA A REDESCOBERTA DO EU SUPERIOR.

A música é um estímulo sonoro, que atua de forma global e individualizada nos campos energéticos humano e ambiental. De acordo com COSTA (1) , a música se caracteriza pela relação entre ritmo, melodia e harmonia, e qualquer alteração em um destes elementos, altera o caráter da composição musical. A autora descreve em seu trabalho cada um dos elementos da composição musical, os quais não são aqui apresentados. Saliento apenas que o ritmo é basicamente a ordenação dos movimentos, formando um elo entre espaço-tempo (um dos conceitos do sistema de Rogers). A música utilizada como intervenção terapêutica pode agir na consciência do cliente, auxiliando na canalização interna de suas energias, explicitando o implícito, despertando a consciência para a redescoberta do eu superior, auxiliando no auto-conhecimento e na auto-transformação. Por outro lado, a música pode acentuar ou diminuir a capacidade das trocas simultâneas de energias entre os CHA. Daí a necessidade de conhecer o cliente e os efeitos da música, e selecionar o ritmo e a música apropriados aos efeitos terapêuticos desejados. Segundo TAME (9), diferentes ritmos de música atuam sobre dif erentes "chakras". Os "chakras", ou centros de força, são vértices energéticos semelhantes a rodas, que se situam na superfície do campo de energia do ser humano (3). Eles funcionam como pontos de conexão através dos quais se dão as trocas de energia entre ser humano e meio ambiente ${ }^{(2)}$. Alguns autores apresentam sete "chakras", dispostos ao longo do campo de energia humana (3) . A Tabela 1 apresenta a associação entre os sete "chakras" com determinadas classes de instnumentos musicais e estilos de música, salientando aquelas músicas que favorecem e aquelas que dificultam o funcionamento do "chakra" (9).

Determinadas peças musicais parecem atuar mais ou menos intensamente na consciência do ser humano, estimulando de forma mais predominante as energias mais densas, as energias dos sentimentos e emoções e as da mente. LINGERMAN (4) apresenta a indicação das diferentes peças musicais de acordo com os diferentes objetivos terapêuticos (ver Anexo).

A opção por incorporar a música no processo de cuidar em enfermagem adveio dos meus estudos e observações sobre os efeitos das diversas peças musicais em meu próprio campo energético e sobre os benefícios que encontro na minha convivência diária com a música. A partir daí, iniciei as mesmas observações ao desenvolver sessões musicoterápicas com diversos clientes, tendo essas se mostrado favoráveis à continuação de sua aplicação.

Com base no sistema conceitual de Rogers e no conceito de "chakras", este artigo aborda a música no processo de cuidar de clientes com Síndrome Neurológica decorrente da AIDS. Embora já tenha desenvolvido este processo com vários clientes (processo de elaboração para posterior publicação), este artigo descreve a experiência com um destes clientes.

O PROCESSO DE CUIDAR COM MÚSICA OPORTUNIZA UM CAMINHAR RUMO A NOVAS EXPERIÊNCIAS, NA BUSCA DO AUTO-CONHECIMENTO E AUTO-TRANSFORMAÇÃO.

A utilização da música no processo de cuidar em enfermagem é ainda incipiente. O processo de cuidar é entendido como um processo de interação dinâmica, intuitivo e criativo entre os campos do cliente-enfermeiro-ambiente (CCEA), oportunizando um caminhar rumo a novas experiências, onde eles, de forma original e única, se auto-conhecem e se auto-transformam (7). "Conseqüentemente, não se pode prever os obstáculos deste caminhar, como também a forma com que ele se efetivará"'(7) .

A partir da minha experiência, tenho observado que a música constitui um instrumento importante para a repadronização dos rítmos dos campos do cliente-ambiente (CCA).

$\mathrm{Na}$ prática, algumas etapas se destacam como necessárias para a efetividade da música no processo 
Tabela 1 - Associação entre os sete "Chakras" e determinadas classes de instrumentos musicais e estilos de música.

\begin{tabular}{|c|c|c|c|c|c|}
\hline $\begin{array}{l}\text { "Chakras" } \\
\text { (Vórtice } \\
\text { energético } \\
\text { que absorve e } \\
\text { emite energia). }\end{array}$ & $\begin{array}{l}\text { Local onde se } \\
\text { situa cada } \\
\text { "chakra" }\end{array}$ & $\begin{array}{l}\text { Qualidade que } \\
\text { o "chakra" } \\
\text { focaliza na } \\
\text { consciência } \\
\text { do homem. }\end{array}$ & \begin{tabular}{|l} 
Instrumentos \\
que influem \\
particularmente \\
no "chakra"
\end{tabular} & $\begin{array}{l}\text { Músicas que } \\
\text { hamonizam } \\
\text { os "chakras" }\end{array}$ & $\begin{array}{l}\text { Músicas que } \\
\text { desamonizam } \\
\text { os "chakras" }\end{array}$ \\
\hline Raíz ou Básico & \begin{tabular}{|l|} 
base da \\
espinha dorsal
\end{tabular} & \begin{tabular}{|l} 
centro de \\
energia vital
\end{tabular} & $\begin{array}{l}\text { tambor, } \\
\text { percussão }\end{array}$ & "souls" & $\begin{array}{l}\text { ritmo de "rock" } \\
\text { e vodu }\end{array}$ \\
\hline Esplênico & região do baço & $\begin{array}{l}\text { absorver e } \\
\text { distribuir } \\
\text { vitalidade }\end{array}$ & $\begin{array}{l}\text { instrumento } \\
\text { de sopro }\end{array}$ & $\begin{array}{l}\text { "chajans" } \\
\text { indiana e } \\
\text { música } \\
\text { devocional } \\
\text { ocidental } \\
\end{array}$ & afro-"spirituals" \\
\hline Gástrico & $\begin{array}{l}\text { região do } \\
\text { estômago }\end{array}$ & vida emocional & órgão & & "blues" \\
\hline Cardíaco & $\begin{array}{l}\text { região } \\
\text { pericordial }\end{array}$ & amor & harpa & \begin{tabular}{|l} 
valsas e \\
música para \\
harpa
\end{tabular} & $\begin{array}{l}\text { foxtrote, } \\
\text { tango, e a } \\
\text { "valsa de jazz" }\end{array}$ \\
\hline Laríngeo & $\begin{array}{l}\text { região da } \\
\text { tireóide }\end{array}$ & \begin{tabular}{|l|} 
vontade ou \\
poder, \\
sensibilidade \\
à forma, ao \\
som e ao ritmo
\end{tabular} & metais & $\begin{array}{l}\text { marchas } \\
\text { (como por ex. } \\
\text { Pompa e } \\
\text { Circunstância } \\
n^{0} \text { s } 1 \text { e 4) }\end{array}$ & $\begin{array}{l}\text { músicas } \\
\text { cantadas de } \\
\text { "rock" e } \\
\text { também de } \\
\text { "folk-rock" }\end{array}$ \\
\hline $\begin{array}{l}\text { Frontal ou } \\
\text { Terceiro olho }\end{array}$ & \begin{tabular}{|l|} 
entre as \\
sombrancelhas
\end{tabular} & $\begin{array}{l}\text { integração } \\
\text { das idéias, } \\
\text { visualização, } \\
\text { centro da } \\
\text { percepção }\end{array}$ & piano & $\begin{array}{l}\text { concertos de } \\
\text { piano }\end{array}$ & $\begin{array}{l}\text { música de } \\
\text { computador } \\
\text { (A “nova } \\
\text { música”) }\end{array}$ \\
\hline Coronário & alto da cabeça & $\begin{array}{l}\text { estação de } \\
\text { consciência, } \\
\text { qualidade } \\
\text { espiritual. }\end{array}$ & cordas & sinfonias & "jazz" \\
\hline
\end{tabular}

de cuidar. Estas etapas são: reconhecimento da dinâmica das relações entre CCA (princípio da integralidade); identificação das disritmias destas relações e seleção do ritmo e da peça musical apropriadas aos ef eitos terapêuticos desejados (princípios da ressonância e helicidade), sincronização dos ritmos dos campos cliente-enfermeiro-ambiente (CCEA) durante o processo de cuidar com música; e avaliação dos ritmos destes campos ao longo do processo (Figura 1). Embora por questões didláticas, o processo de cuidar com música esteja dividido em etapas, na prática elas podem ocorrer, muitas vezes, simultaneamente e num processo contínuo e dinâmico de ir e vir.
Todas as etapas devem ser desenvolvidas em conjunto com o cliente e/ou familiares e/ou pessoas do campo ambiental do cliente.

O reconhecimento da dinâmica das relações estabelecidas é a primeira etapa e possibilita o enf ermeiro identificar o ritmo dos CCA, a partir das manifestações destes campos, bem como, compreender as reações individualizadas e únicas de cada campo a uma determinada peça musical. Algumas manif estações do rítmo os CCA, as quais influenciam as necessidades e preferências musicais, de acordo com Lingerman $^{(4)}$, são: temperamento, reações sensoriais, padrões de comportamento, lembranças da infância, 
Figura 1 - Esquema do processo de cuidar com música desenvolvido por Silva (1990), com base em Rogers.
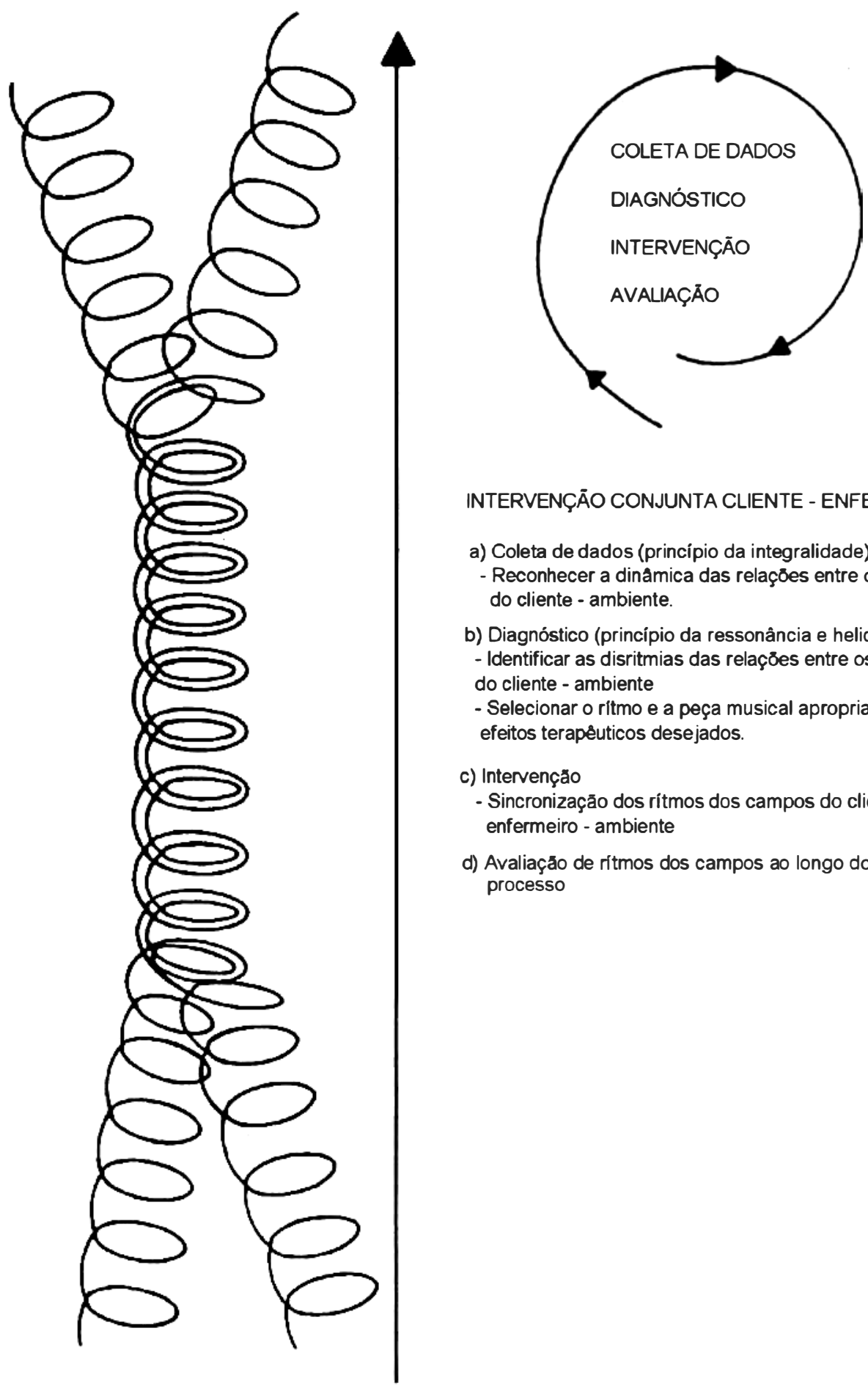

INTERVENÇĀO CONJUNTA CLIENTE - ENFERMEIRO

a) Coleta de dados (princípio da integralidade) - Reconhecer a dinâmica das relaçóes entre os campos do cliente - ambiente.

b) Diagnóstico (princípio da ressonância e helicidade) - Identificar as disritmias das relaçőes entre os campos do cliente - ambiente

- Selecionar o ritmo e a peça musical apropriados aos efeitos terapéuticos desejados.

c) Intervençăo

- Sincronização dos rítmos dos campos do cliente enfermeiro - ambiente

d) Avaliaçăo de rítmos dos campos ao longo do processo

PROCESSO VITAL DOS CAMPOS

ENERGÉTICOS: CLIENTE - ENFERMEIRO. 
ambiente familiar e do trabalho, desejos e aspirações intensas, e os ideais que são perseguidos mais ardentemente.

A identificação das disritmias é uma etapa que se segue ao reconhecimento da dinâmica das relações estabelecidas, embora possa ocorrer, muitas vezes, simultaneamente. as disritmias constituem interferências dissonantes na relação entre $\mathrm{CHA}$ e trazem para o homem desconforto, doença e morte. As disritmias do campo energético do cliente estão diretamente ligadas às disritmias dos "chakras". Assim, um cliente com imunodepressão e estresse deverá ter um estímulo harmonizador mais voltado para os "chakras" esplênico e gástrico. Entretanto, todos os outros "chakras" deverão ser harmonizados, visto que são independentes e interrelacionados. Deste modo, uma disritmia em um dos "chakras" poderá gerar disritmias em todos os outros "chakras". A peça musical a ser selecionada deverá ter um rítmo lento e de preferência com instrumentos de sopro e órgão. A intuição tem um papel de destaque na seleção de uma peça musical, principalmente quando não é possível contactar verbalmente com o cliente e/ou familiares e/ou pessoas do campo ambiental do cliente.

Ao utilizar a classificação pıoposta por LINGERMAN (4) (Anexo), detectei que determinadas peças musicais sugeridas para agir de determinada forma, nem sempre produzem o ef eito esperado nos diversos clientes. Deste modo, o enfermeiro deverá pesquisar na classificação a peça musical e o rítmo mais apropriados aos efeitos terapêuticos desejados.

A sincronização dos rítmos dos CCEA durante o processo de cuidar com música, é uma condição importante que o enfermeiro adquire à medida que desenvolve sua sensibilidade à música. Sincronizar implica em uma condição interior de sentir e captar a vibração rítmica do outro ser. Para tanto é necessário um ambiente silencioso e sem interrupções, posição confortável e receptividade dos CCEA à peça musical. Antes de iniciar a sessão de musicoterapia, o enfermeiro deverá se concentrar em seu próprio corpo energético e avaliar o ritmo do seu padrão de campo, e se necessário buscar harmonizá-lo. A seguir, ele avaliará o ritmo do padrão de CCA. Durante todo o processo de cuidar com música o enfermeiro procurará estar sincronizado com o cliente e ambiente.
Quando a sincronização rítmica é efetivada, a experiência do compartilhar é vivenciada. Assim, clienteenfermeiro-ambiente, sob a vibração rítmica da música, tornam-se um único campo energético, um centro de força integrada. A unidade é alcançada. Nos momentos iniciais, quando a sincronização é efetivada, o enfermeiro poderá sentir-se tenso, deprimido, angustiado e muitas vezes com dor. Entretanto, ao longo do processo de cuidar, se a peça musical escolhida foi apropriada, estas sensações cederão lugar a outras mais harmônicas, como a de calma, paz, bem estar e alegria.

A avaliação deve se fazer presente ao longo do processo de cuidar com música. Entretanto, no final de cada sessão musicoterápica, ela se destaca, quando enfermeiro e cliente compartilham suas experiências. Caso isto não seja viável, a exemplo dos clientes com danos cerebrais, o enfermeiro se guiará pelas sensações dos clientes durante o processo. Cada experiência é única, original e enriquecedora. Não existem regras definidas, somente com a prática o enfermeiro poderá desenvolver sua habilidade, sensibilidade e estilo próprio de cuidar com música.

O PROCESSO DE CUIDAR COM MÚSICA REQUER DO ENFERMEIRO INTUIÇÃO, CRIATIVIDADE, SENSIBILIDADE E ESTILO PRÓPRIO DE CUIDAR.*

\section{Apresentando Davi**}

Iniciei o cuidado a Davi no dia 07 de abril de 1989. Logo de início, ele se revelou a mim como um ser muito especial. Contava naquela época com 53 anos de idade, alta estatura $(1,90 \mathrm{~m})$ e um peso proporcional a sua altura $(80 \mathrm{Kg})$. Seus cabelos grisalhos eram curtos, lisos e de textura grossa. Em sua face sobressai-se a pele clara, olhos grandes de cor castanha escura e o nariz grande afilado. Vestia-se com elegância e fazia-se sempre acompanhar de um chapéu de feltro e de uma bengala de madeira.

Trabalhava em publicidade e demonstrava ao falar um grande domínio de conhecimento acerca de sua área profissional, de outras áreas do conhecimento e do processo saúde-doença da AIDS.

\footnotetext{
* Este processo foi relatado na dissertação de mestrado "Experienciando o cuidar do cliente com AIDS, com base no sistema conceitual de Rogers", 1990.

** O nome do cliente foi alterado para assegurar o anonimato.
} 
Davi era casado, com três filhos, tendo sido a sua relação com a esposa bastante conflituosa ao longo da vida de casado.

\section{Processo Vital de Davi}

Nos encontros iniciais pude conhecer parte da evolução do processo vital de Davi (ver Figura 2).

Davi sof reu um enfarte em 1982 e em decorrência submeteu-se a uma revascularização do miocárdio. Naquele período recebeu transfusão sanguínea, tendo, conseqüentemente, contraído o vírus da AIDS. Entretanto, ele somente soube deste fato em junho de 1988, quando contraiu meningite por criptococus neoformans. Permaneceu hospitalizado quase seis meses.

Segundo Davi, após o diagnóstico da AIDS sua vida desmoronou. A sua relação com a esposa, que já era bastante conflituosa, passou praticamente a inexistir. Ao retomar para casa passou a sof rer total rejeição por parte de sua esposa.

No trabalho, Davi também sentiu-se rejeitado a partir do momento que revelou o seu diagnóstico aos diretores da empresa. Seu local de trabalho foi transferido para sua residência, a fim de evitar que o seu diagnóstico interferisse nos negócios da empresa. Os trabalhos de responsabilidade lhe foram retirados.

As orientações fornecidas pelo seu médico aos seus familiares e diretores da empresa acerca do processo saúde-doença da AIDS, não contribuíram para que eles modificassem os seus comportamentos.

Por outro lado, após a meningite, Davi percebeu que a sua capacidade para o trabalho sof reu uma acentuada redução, por não conseguir mais ser criativo, apresentar freqüentes falhas de memória e cansarse com facilidade.

Davi apresentava uma grande oscilação do seu estado psicológico. Preocupava-lhe muito o seu estado de saúde, a situação de conflito com sua esposa, a sua incapacidade para o trabalho e os rumos que a sua vida tomaria. Estas preocupações acarretavam-lhe insônia, pesadelos, depressão e indisposição física. Os freqüentes lapsos de memória, seqüela da meningite, o angustiavam. Deparava-se com situações embaraçosas, quando ao conversar com pessoas, esquecia-se quem eram e do que estavam falando. Quando fazia sua caminhadas, em determinados momentos não sabia como retomar à sua casa. Conforme o cliente, esses lapsos de memória embora freqüentes, ocorriam durante um período de tempo muito peque- no, voltando logo a ter um controle da situação.

Davi sentia que estar com AIDS era uma condição muito desgastante e irreversível, um caminho sem volta, que lhe acarretou inúmeras mudanças em suas crenças e valores acerca da vida e da morte. Com a doença sentiu a morte próxima e, conseqüentemente, procurou mudar o seu esquema de vida, esforçandose para não se preocupar com o tempo que lhe restava, mas sim com a qualidade de vida. Passou a se interessar mais pelo aspecto espiritual de sua vida. Em se tratando da morte, Davi sempre acreditou que com ela, tudo se acabava. Todavia, após a doença passou a ter sérias dúvidas e muitas vezes chegava a acreditar que existia vida após a morte, mas procurava não se preocupar com isto, pois quando chegasse a hora saberia. Davi sentia que este momento estava bem próximo e se estivesse certo não seria surpreendido, visto que viver uma vida sem surpresas era bem mais confortável.

\section{Processo Terapêutico}

No primeiro encontro apresentei e expliquei detalhadamente o tipo de trabalho a que me propunha, a necessidade de participação efetiva do cliente no processo e, assim, estabelecemos uma relação contratual verbal.

Acompanhei a evolução do processo vital de Davi durante sete meses, quando se deu a alteração rítmica do seu processo vital nesta dimensão da vida.

Nos encontros que ora aconteciam em sua residência, ora no hospital, procurava, além dos cuidados físicos, estimular as reflexões do cliente acerca das suas crenças e valores sobre o processo vida-morte, saúde-doença. Incentivava as suas reflexões com fins ao autoconhecimento, buscando fortalecer os aspectos harmônicos do seu "eu" e levando-o a eliminar os desarmônicos. Buscava também levá-lo a conscientizar-se da sua responsabilidade no seu processo vital. Davi verbalizava os seus medos e inseguranças, a dificuldade de aceitar as suas limitações, de lidar com os seus sentimentos, emoções e com as modificações no seu padrão de vida, pois evidenciava o desconhecido e o deixavam inseguro.

Nos encontros com Davi, desenvolvíamos a técnica de relaxamento com música. Utilizávamos músicas apropriadas para harmonizar os "chakras" gástricos (emoções), cardíaco (amor) e o frontal (integração das idéias e centro da percepção). $O$ estilo de música escolhida era o clássico, com os seguintes instrumentos: órgão, harpa e piano. Inicialmente, 
Figura 2 - Esquema do processo vital de Davi.

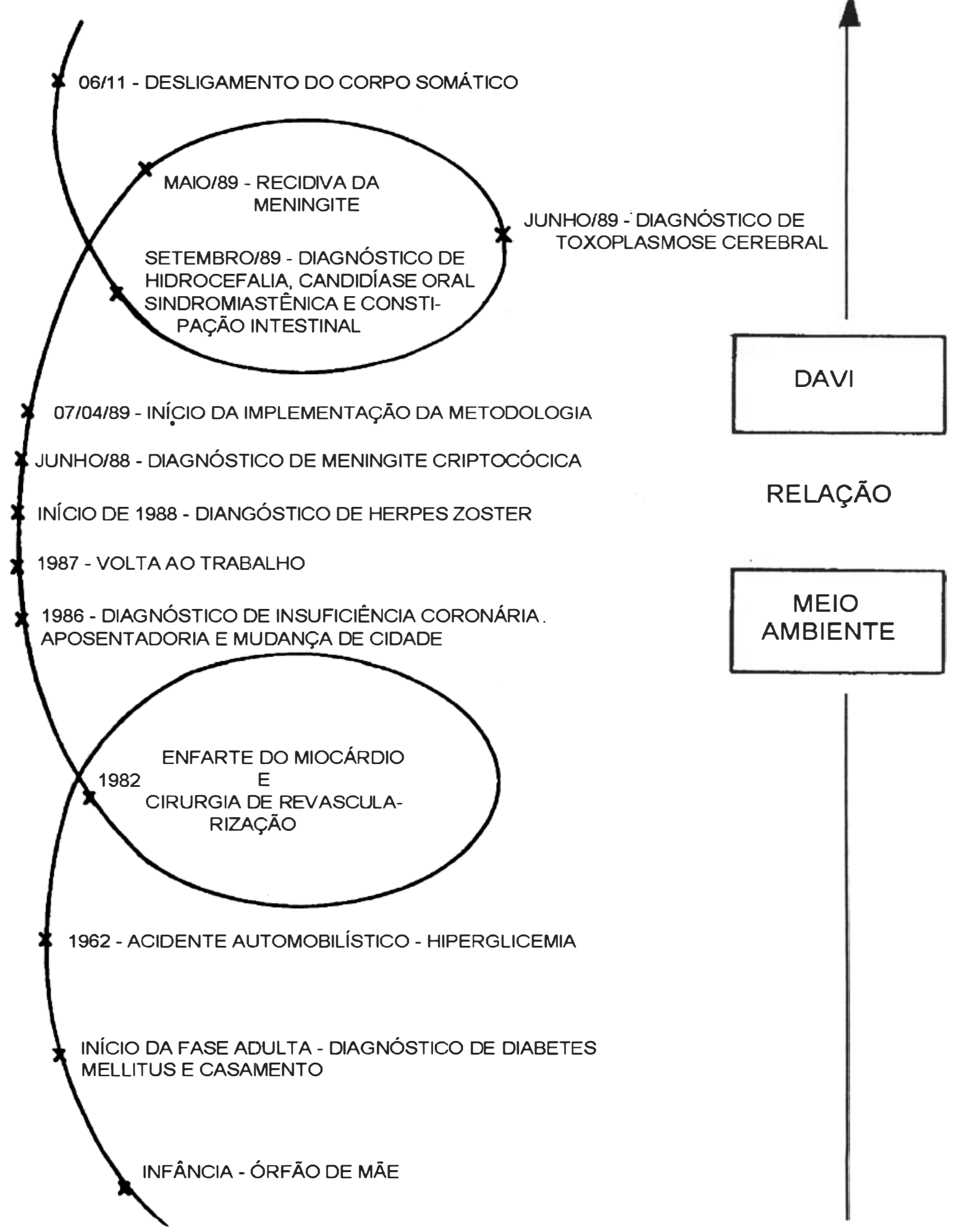


Davi apresentou muita dificuldade para relaxar, tendo ele atribuído esta dificuldade ao fato de ter vivido em constante estado de tensão. Na medida em que as sessões de musicoterapia ocorriam, pude perceber que a música sacra harmonizava mais intensamente o ritmo do campo energético de Davi. Ele demonstrava uma preferência especial por este estilo de música, pois lhe induzia sentimentos de amor, paz e bem estar, além de vitalizar as suas energias mais densas.

Nos encontros com a esposa de Davi e com seu filho, estimulava-os à reflexão sobre todo o processo vivenciado por eles, e procurava infundir-lhes confiança e coragem.

Em maio daquele ano, Davi teve uma recidiva da meningite e em junho apresentou toxoplasmose cerebral. Ele encontrava-se muito debilitado, não conseguindo manter o equilíbrio ao andar. Conseqüentemente, permanecia a maior parte do tempo deitado, só caminhando com ajuda. Eu percebia que dia a dia, a capacidade mental de Davi diminuía e os lapsos de memória se acentuavam. Durante os diálogos, em vários momentos, ele ficava alheio ao ambiente, não conseguindo se situar no assunto do momento. Em vários encontros a música era a linguagem compartilhada por nós. Naqueles momentos permanecia ao seu lado, tocando-o e transfundindo-lhe energias. Às vezes Davi olhava-me longamente, sorria e apertava minha mão.

Os familiares de Davi passaram a auxiliá-lo nas suas necessidades e a permanecer mais tempo com ele. Aproveitava os nossos encontros para estimulálos a verbalizarem os seus sentimentos e inf undir-lhes confiança e coragem.

Em setembro, Davi internou-se por apresentar, além do quadro anterior, hidrocefalia e síndrome astênica importante. No período que se seguiu à sua internação, Davi apresentou períodos de lucidez intercalados com períodos de confusão mental e alheio ao meio ambiente. Nos momentos de lucidez, ele verbalizava as suas angústias e medos em relação à morte. Ele sentia que aquele momento estava próximo. Eu procurava estimular a sua confiança no ser superior em que ele acreditava, e em si mesmo, como capaz de superar aqueles medos e angústias. Davi demonstrava-se sentir-se mais calmo e abordava a sua crença de que continuaria a viver após aquela passagem. Ele referia tanıbém que a doença e o sof rimento o estavam ensinando a ser mais paciente, tolerante e menos egoísta. Estava aprendendo a aceitar as suas limitações, a conviver com os seus sentimentos e emoções. Ele conseguia entender que toda aquela situação presente era decorrente de sua forma de ser e de viver. Por outro lado, Davi percebia o quanto havia contribuído para a existência de conflitos entre ele e sua esposa. Detectava a sua falta de amor, carinho e compreensão em relação aos seus familiares. Naquele periodo, eu evidenciava-lhe a importância daquela situação para o seu auto-conhecimento e auto-transformação.

Nos dias que se seguiram Davi foi se desligando do meio ambiente. Permanecia grande parte do tempo com os olhos fixos em algum ponto. Quando questionado, não conseguia elaborar seus pensamentos. Nas sessões de musicoterapia, quando procurava sincronizar o ritmo de meu campo ao dele, sentia-me, inicialmente, profundamente só e deprimida. Entretanto, ao longo da sessão, aquelas sensações eram substituídas por calma e paz. Percebia que Davi se transformava com a música, seus músculos se descontraiam e a expressão de sua face e de seu olhar demonstrava serenidade. Eu percebia que através da música conseguia aumentar as trocas de energia entre Davi e o ambiente e inf undir-lhe coragem e tranqüilidade. Nos poucos momentos de lucidez, ele confirmava as minhas percepções referindo que se sentia muito só e deprimido, mas nos momentos que passávamos juntos ele conseguia se sentir mais seguro e em paz. Aproveitava aqueles poucos momentos para infundirlhe confiança, força e mostrar-lhe o quanto o admirava por sua coragem em superar aqueles momentos difíceis. Davi sorria e se emocionava.

No dia 06 de novembro Davi partiu. Permaneci algum tempo ao lado do seu corpo físico e orei. Senti que ele havia partido em paz. A expressão de sua face confirmava a minha percepção. Detectava naquela expressão a serenidade e o leve sorriso deixado por um ser humano que havia conseguido superar as suas dificuldades com coragem e dignidade. Ao confortar a esposa de Davi, ela referiu sentir-se em paz por terem conseguido superar as mágoas e dificuldades do relacionamento e caminhar com ele até os seus últimos momentos.

\section{O PROCESSO DE CUIDAR COM MÚSICA, SUBSI-} DIADO POR ROGERS É UM CAMPO PROMISSOR PARA A ENFERMAGEM.

A partir de minha prática, pude detectar que o sistema conceitual de Rogers, confere ao processo de cuidar uma forma mais humanística, avançada e efetiva quando comparada ao modelo biomédico. Os conceitos e princípios da homeodinâmica, propostos por Rogers, são operacionalizáveis na prática e faci- 
litam a compreensão e a utilização da música na repadronização dos ritmos dos campos do cliente-enfermeiro-ambiente. A música, por sua vez, constitui um instrumento valioso no processo de cuidar de clientes com síndrome neurológica, especialmente quando estes clientes se encontram incapacitados para manifestar suas consciências. Os resultados observados neste processo e advindos de outros nos quais atuei, levam-me a acreditar que o processo de cuidar com música, subsidiado pelo sistema conceitual de Rogers, é um campo promissor para a cufcrmagem e que merece ser estudado e pesquisado.

\section{REFERÊNCIAS BIBLIOGRÁFICAS}

1. COSTA, M.C. O despertar para o outro-Musicoterapia. São Paulo: Summus Editorial, 1989.

2. KARAGULLA, S. et al. Os chakras e os campos de energia humanos. Trad. Claúdia Gerpe Duarte. São Paulo: Pensamento, 1989.

3. LEADBEATER, C. W. Os chakras. Os centros magnéticos vitais do ser humano. Trad. J. Gervásio de Figueiredo. São Paulo: Pensamento, 1989.

4. LINGERMAN, H. A. As energias curativas da musica. Trad. Claúdia Gerpe Duarte. São Paulo: Cultrix, 1990.

5. PRINCE, R. W. et al. The brain in AIDS. Central Nervous System. HIV-1 infection and AIISS dementia complex. Science, v. 239, n. 4840, p. 586-92, feb., 1988.
6. ROGERS, M. E. An introduction to the theorical hasts of nursing. Philadelphia: F. A. Davis Co. 1970.

7. SILVA, A.L. Experienciando o cuidar do cliente com AIDS. com base no si stema conceitual de Rogers. Dissertação de Mestrado apresentada ao curso de Pós-Graduação em Enfermagem da UFSC, Florianópolis, 1990.

8. SUNDER, J. A. AIDS - a neurological nursing challenge. In: HIELLER, B. R. (ed.). Acquired immune deficiency syndrome. AIDS. Topics in clinical nursing, v. 6. n. 2, p. 67-71, july, 1984

9. TAME, D. O poder oculto da música. A transformação do homem pela energia da misica. Trad. Octavio Mendes Cajado. São Paulo: Cultrix, 1984. 


\section{ANEXO: MUSICOTERAPIA}

(Lingerman, 1990)

\section{Para harmonizar as energias mais densas}

Brahms: Danças Húngaras - Mendelssohn: Sonhos de Uma Noite de Verão - Mozart: O Rapto do Serralho; Don Giovanni e a Flauta Mágica - Schubert: Marcha Militar - Tchaikovsky: "danças" de O Lago dos Cisnes e de A Bela Adormecida; Marcha Eslava - Verdi: Marcha Triunfal (de Aída) - Wagner: Os Mestres Cantores - Weber: Convite à Valsa Beethoven: Marcha Turca (de As Ruínas de Atenas) - Dvorák: Danças Eslavas - Rossini: A Escada de Seda - Strauss: O Morcego.

\section{Para harmonizar as energias da mente}

Bach: Concerto de Brandenburgo; O Cravo Bem Temperado; Música Orquestral - Haendel: Música Aquática - Brahms: Concerto para Violino/Trilha Sonora; Born Free/Sinos Tibetanos - Telemann: Concerto para Três Violinos e Orquestra - Scarlatti: Sonatas para Cravo - Música Barroca para Cordas de Felemann, Vivaldi, Albinoni, Corelli e Torelli.

\section{Para harmonizar energias dos sentimentos e emoções}

\section{Liberar a raiva.}

Bach: Dois Concertos para Dois Pianos - Haendel: Concerto para Harpa - Schubert: Prelúdio para Rosamunda - Tchaikovsky: Sinfonia $\mathrm{n}^{\circ} 5$ (último movimento) - Brahms: Concerto para Piano ${ }^{\circ} 1$ Van Eyck: Música para Flauta de Bico - Dexter: Viagem Dourada I - Gluck: Dança dos Espíritos Bem-Aventurados - Dawland: Você e o Oceano Saint-Saëns: Sinfonia n 3 (órgão), último movimento - Reiberger: Concerto para Órgão - Wagner: A Cavalgada das Valquírias.

\section{Aliviar a tensão.}

Bach: Ária para a Corda do Sol - Becthoven:
Sinfonia $n^{\circ} 6\left(1^{\circ}\right.$ e $2^{\circ}$ movimentos $)$ - Mozart: Concerto para Flauta e Harpa - Vivaldi: Concerto para Flauta; As Quatro Estações - Giuliani: Concerto para Violão - Mantovani.

\section{Propiciar Força e Coragem.}

Beethoven: Concerto para Piano $\mathrm{n}^{\circ} 5$ (O imperador); Fantasia do Coral para Piano e Orquestra Brahms: Sinfonia $\mathrm{n}^{\circ} 2$ (Movimento Final) - Strauss: O Nascer do Sol ( de Assim Falou Zarathustra) Elgar: Pompa e Circunstância $n^{\circ} 1$ - Copland: Um Retrato de Lincoln; Suite de Velhas Canções Americanas.

\section{Propiciar Devaneio.}

Wagner: Estrela Vésper - Zamfir: A Flauta Romântica de Pan - Debussy: Clair de Lune; Danças Sagradas e Profanas para Harpa e Orquestra - Ravel: Pavane para uma Princesa Morta - Halpern-Kelly: Ecos Antigos - Stivell: Renascimento da Harpa Celta - Vivaldi: Concertos para Oboé - Copland: Cidade Quieta; Primavera nos Apalaches.

\section{Superar o Medo e a Depressão.}

Beethoven: Concerto para Piano $\mathrm{n}^{\circ} 5$ ( $\mathrm{O}$ imperador) - Dvorák: Sinfonia $\mathrm{n}^{\circ} \mathrm{8}$; Danças Eslavas Mozart: Sinfonia $n^{\circ} 35$ (Haffner) - Haendel: Música Aquática; Música dos Fogos de Artifício do Rei; Corais do Messias e de Israel no Egito - Mendelssohn: Sinfonia ${ }^{\circ} 4$ (Italiana) - Rachmaninoff: Concerto para Piano $\mathrm{n}^{\circ} 2$ (movimento final).

\section{Aliviar o Tédio.}

Liszt: Rapsódias Húngaras - Haydn: Concerto para Trompete - Respighi: Danças e Árias Antigas; Os Pinheiros de Roma. 